Research Paper

\title{
In vitro Protease Inhibition and Cytotoxicity of Aspergillus fumigatus Biomolecules Secreted under Long-Term Aerated Conditions
}

\author{
Valentina S. Arsic Arsenijevic ${ }^{\circledR}$, Marina G. Pekmezovic ${ }^{1}$, Katarina M. Rajkovic ${ }^{2}$, Berislav P. Vekic ${ }^{3,4}$, \\ Aleksandra M. Barac ${ }^{1}$, Suzana Tasic-Otasevic ${ }^{5}$, Ljubica Dj. Petkovic ${ }^{6,7}$ \\ 1. National Reference Medical Mycology Laboratory, Institute of Microbiology and Immunology, Faculty of Medicine, University of Bel- \\ grade, dr Subotića 1, 11000 Belgrade, Serbia \\ 2. High Chemical and Technological School for Professional Studies, Kosančićeva 36, 37000 Kruševac, Serbia \\ 3. Clinical Centre “Dr Dragiša Mišović” Department of Surgery, Milana Tepića 1, 11000 Belgrade, Serbia; \\ 4. University of Alfa, Palmira Toljatija 3, 11000 Belgrade, Serbia \\ 5. Institute of Microbiology and Immunology, Faculty of Medicine, University of Nis, Bulevar Dr Zorana Djindjica 81, 18000 Nis, Serbia \\ 6. Institute of Microbiology and Immunology, Faculty of Medicine, University of Ljubljana, Zaloška 4, 1000 Ljubljana, Slovenia \\ 7. Gynecology Department Grajska ulica 24, 9000 Murska Sobota, Slovenia
}

$\bowtie$ Corresponding author: Valentina S. Arsić Arsenijević. E-mail: mikomedlab@yahoo.com; tel: +381-11-3643-242; fax: +381-11-2685-584

( ) Ivyspring International Publisher. This is an open-access article distributed under the terms of the Creative Commons License (http://creativecommons.org/ licenses/by-nc-nd/3.0/). Reproduction is permitted for personal, noncommercial use, provided that the article is in whole, unmodified, and properly cited.

Received: 2013.12.10; Accepted: 2014.07.0I; Published: 2014.08.19

\begin{abstract}
The fatality rate of invasive aspergillosis (IA) is still very high, especially in prolonged and untreated pulmonary cases. Aspergillus fumigatus is the main causative agent of IA and investigation of its metabolites could provide valuable insight into virulence factor(s) associated with this organism. We evaluated the $A$. fumigatus culture filtrate (CF) products generated during short- and long-term aerated and non-aerated conditions and tested for (i) inhibition of cysteine or serine proteases and (ii) cytotoxicity. In addition, the mathematical model was determined using response surface methodology (RSM) to estimate the influence of different fermentation conditions on A. fumigatus CF characteristics, predict enzyme inhibition and make possible correlations with in vivo conditions. Biosynthesis of A. fumigatus low molecular weight proteinaceous products (from 6.4 to 15.4 $\mathrm{kDa}$ ) was observed after 6 days of growth under aerated and alkaline conditions. Also, only these CFs showed significant reduction in cell lines survival (Caco-2 and WISH $35.6 \%$ and $54.6 \%$, respectively). Obtained results provide solid starting point for further studies that would include: (i) detailed chemical characterization of $A$. fumigatus CF, (ii) activity relationships and in vivo correlation with pathogenicity of prolonged pulmonary IA and (iii) possible use of biomolecules as diagnostic or therapeutic markers.
\end{abstract}

Key words: Aspergillus fumigatus, culture filtrate, oxygen, cytotoxicity, cysteine protease inhibition

\section{INTRODUCTION}

There is a diverse set of illnesses caused by Aspergillus, ranging from chronic colonization, aspergilloma, invasive aspergillosis (IA) or hypersensitivity $[1,2]$. Aspergillus fumigatus is the main causative agent of aspergillosis responsible for approximately $90 \%$ of all cases, including often chronic diseases such as IA and aspergilloma [3]. Lungs are the primary and the most commonly affected organ making pulmonary IA a serious problem, especially in critically ill patients. The disease lasting longer than 10 days and without treatment is often fatal, especially in high risk and immunocompromised patients [2, 4]. However, aspergilloma is usually a non-invasive form, characterized by low local oxygen availability and it has better 
outcome, especially after a surgical treatment [5].

A. fumigatus posses a number of virulence factors, including metabolites secreted into the extracellular environment during mating that provide benefits for its growth [6]. More than 226 secreted compounds are detectable in A. fumigatus culture filtrate (CF), such as gliotoxin [7, 8] trypacidin [9], fumigaclavin $\mathrm{C}$, aurasperon $\mathrm{C}$, helvolic acid, fumagilin, Asp-hemolysin and ribotoxins [10]. They might function as virulence factors, or their presence could give a competitive edge to the producing organism or enhance the survivability of spores [11].

A. fumigatus pathogenicity is quite complex [12]. It was shown that $A$. fumigatus excretes proteases or their inhibitors in later stages of infection which can lead to serious tissue damage [13]. Furthermore its pathogenic mechanisms are partially mediated through inhibition of host proteases [12]. Beside the fact that pathogen-derived protease inhibitors can significantly contribute to severity of an infection, the information about small molecule peptidase inhibitors of fungal origin is limited [14]. Previous in vitro studies demonstrated cytotoxicity of $A$. fumigatus $\mathrm{CFs}$ against macrophages [13, 15], human nasal epithelial [16] and human umbilical vein endothelial cells [17]. Anticancer activity of $A$. fumigatus metabolites $[18,19]$ and cytotoxicity of its spore-borne metabolite to A549 tumor lung cell line were also shown [9].

Many factors influence the production of $A$. fumigatus metabolites that are important for its pathogenicity, including aeration, temperature, $\mathrm{pH}$ level, duration of fermentation, exposure to light and medium composition [20, 21, 22]. However, in vitro conditions that promote production of low molecular weight molecules under long-term aerated conditions associated with biology effects have not been thoroughly elucidated. Therefore, the aim of the study was to investigate influence of $\mathrm{O}_{2}$ tension, both under short and long-term fermentation on of A. fumigatus biomolecules production and their association with protease inhibition and cytotoxicity. In addition, a response surface methodology (RSM) was used to estimate the influence of different conditions on the $A$. fumigatus CFs characteristics, to predict enzyme activity and to possibly indicate correlations with in vivo conditions.

\section{MATERIALS AND METHODS}

\section{Preparation of $A$. fumigatus CF samples}

A. fumigatus ATCC 13073 strain was obtained from the American Type Culture Collection. It was grown for five days on Sabouraud dextrose agar (SDA) (Oxoid, Basingstoke, United Kingdom) at $30^{\circ} \mathrm{C}$. After a five-day period of incubation, A. fumigatus conidia were collected and resuspended in minimal essential medium (MEM) (Sigma Chemical Co., M4655, St. Louis, MO) at the concentration $1 \times 10^{6}$ $\mathrm{CFU} / \mathrm{mL}$. MEM was used instead of complex and rich media, because it facilitates the detection of secreted products. Media with fetal calf serum (FCS) can mask small secreted molecules and make their detection impossible. Sixty milliliters of conidial suspension were put into $250-\mathrm{ml}$ flasks, incubated under oxygen $\left(20 \% \mathrm{O}_{2}\right)$ and non-oxygen $\left(0 \% \mathrm{O}_{2}\right)$ conditions at $37^{\circ} \mathrm{C}$ with agitation at $140 \mathrm{rpm}$. Six different $A$. fumigatus CF samples were collected by centrifugation: (i) under aerated conditions on days 1, 3 and 6 (A. fumigatus $\mathrm{CF}$ AE-1; A. fumigatus CF AE-3; A. fumigatus CF AE-6, respectively) and (ii) under non- aerated conditions on days 1, 3 and 6 (A. fumigatus CF AN-1; A. fumigatus CF AN-3; A. fumigatus CF AN-6, respectively). Supernatants were filtered through a 0,22 $\mu \mathrm{m}$ Millipore filters and stored at $-20^{\circ} \mathrm{C}$ until use.

\section{Protein-biomolecules detection in A. fumigatus CF samples}

A. fumigatus $\mathrm{CFs}$ protein concentration was determined by the Bradford method [23]. The A. fumigatus CF samples were concentrated 10-fold and analyzed by sodium dodecyl sulfate-polyacrylamide gel electrophoresis (SDS-PAGE). An equal amount of proteins was loaded on gel in the volume of $20 \mu \mathrm{l}$ to allow samples comparison. SDS-PAGE was performed with $75 \mathrm{~g} / \mathrm{L}$ polyacrylamide gel under reducing conditions using standard protein markers (BioRad, France): aprotinin (6.5 kDa), lysozyme (14.5 $\mathrm{kDa})$, trypsin inhibitor $(21.5 \mathrm{kDa})$, carbonic anhydrase (31 kDa), ovalbumin (45 kDa), bovine serum albumin (BSA, $67 \mathrm{kDa}), \beta$-galactosidase $(116 \mathrm{kDa})$ and myosin (200 kDa). Gels were stained with silver [24] and densitometry of stained gels was performed using Image J $1.45 \mathrm{~s}$ software package.

\section{A. fumigatus CF samples characterization}

(i) Determination of $A$. fumigatus $\mathrm{CFs} \mathrm{pH}$ was done by using the apparatus HI 9017 microprocessor $\mathrm{pH}$ meter (HANNA Instruments, Singapore);

(ii) Determination of A. fumigatus CFs effect on serine proteases: Trypsin-like proteolytic activity was determined toward low-molecular weight substrate $\mathrm{N}^{\alpha}$-benzoyl-arginine-p-nitroanilide (BAPNA, Merck), according to the definition that one unit hydrolyzes $1.0 \mu \mathrm{mol}$ of BAPNA per minute at $\mathrm{pH} 6.2$ at $25^{\circ} \mathrm{C}$ [25];

(iii) Determination of $A$. fumigatus $\mathrm{CFs}$ effect on cysteine proteases: Papain-like proteolytic activity was determined toward $\mathrm{N}^{\alpha}$-Benzoyl-L-Arginine Ethyl Ester (BAEE, Sigma Aldrich) according to the definition that one unit hydrolyzes $1.0 \mu \mathrm{mol}$ of BAEE per minute at $\mathrm{pH} 6.2$ at $25^{\circ} \mathrm{C}$ [25]. 
The effect of $A$. fumigatus CF samples on trypsin and papain like proteases, was investigated by adding $0.2 \mathrm{ml}$ of CF samples in incubation mixture, and after incubation at $37^{\circ} \mathrm{C}$ for $15 \mathrm{~min}$, the absorbance was monitored at $405 \mathrm{~nm}$. Inhibition of proteases activity was expressed as the percentage of initial activity (mixture without $A$. fumigatus $\mathrm{CFs}$ ), which was considered as $100 \%$ activity. Spectrophotometric measurements were done on Beckman DU-640 spectrophotometer (Beckman Instruments Inc., Fullerton, CA, USA).

\section{Preparation of Caco-2 and WISH cell lines for cytotoxic assays}

The cell lines were obtained from American Type Culture Collection. Both Caco-2 (human intestinal epithelial cell line) and WISH (contaminant of HeLa cervical cancer cells) are widely used and well validated, and they could represent general cytotoxicity with similar sensitivity as many other cell lines $[26,27]$. Cells were cultured in MEM supplemented with 10\% (v/v) FCS (GIBCO Laboratories, Paisley, Scotland) and grown in $80 \mathrm{~cm}^{2}$ tissue culture flasks at $37^{\circ} \mathrm{C}$ and $5 \% \mathrm{CO}_{2}$ in a humidified atmosphere and routinely subcultured by trypsinization every 3-4 days.

\section{Cytotoxic assay on Caco-2 and WISH cell lines with $A$. fumigatus CF samples}

Caco-2 and WISH cells were seeded at initial density of $2 \times 10^{4}$ cells/well in flat-bottom 96-well tissue culture plates. Cells were cultivated together with series of two-fold dilutions of $A$. fumigatus $C F$ samples (concentrations of $0.78 ; 1.56 ; 3.12 ; 6.25 ; 12.5$; 25 and $50 \%$ ) in quadruplicate in appropriate media ( $5 \% \mathrm{CO}_{2} ; 37^{\circ} \mathrm{C}$; humidity). Cells without $A$. fumigatus $\mathrm{CF}$ added were used as control. After 2 days, the cells were washed three times with phosphate buffered saline (PBS), and then fixed to the plates with 50 $\mu \mathrm{l} /$ well of $100 \%$ ethanol for $5 \mathrm{~min}$ at room temperature. Fixed cells were washed and stained with $1 \%$ crystal violet stain. Stained cells were washed, lysed and solubilized with $33.3 \%$ acetic acid solution. Optical density (OD) of developed purple color was read at $450 \mathrm{~nm}$. OD was taken as index of proliferation of Caco-2 and WISH cells. OD values were expressed as inhibition rate $(\mathrm{IR} \%)$ relative to the untreated control cells.

\section{Mathematical model and statistical analysis}

The RSM is a second-order polynomial equation, developed to correlate $\mathrm{pH}$ level or proteases inhibition with level of oxygen and duration of A. fumigatus fermentation. A design of experiments with three replications was employed.
The second-order polynomial model is presented by the following equation:

$$
y=a_{0}+a_{1} t+a_{2} O+a_{12} t O+a_{11} t^{2}
$$

where $(y)$ is the $\mathrm{pH}$ or inhibition of proteases, $(O)$ is the oxygen level, $(t)$ is the time, $\left(a_{i}\right)$ are the parameters of equation (1) obtained using the multiple nonlinear regression method, $\left(a_{0}\right)$ is the regression coefficient, and $\left(a_{i}\right)\left(a_{i i}\right)\left(a_{i j}\right)(\mathrm{i}, \mathrm{j}=1,2,3, .$.$) are linear, quadratic$ and interactive regression coefficients, respectively. Computer software Design Expert 8.07 (Demo version) was used to perform the statistical analysis of the experimental data. The statistical significance of the models as well as the independent variables and their interactions were estimated by the analysis of variance (ANOVA). ANOVA was determined by Fisher test $(F)$ and the performance of the developed models was statistically measured by the coefficient of determination $(R)$. Student $t$ test was used to analyze the data for cytotoxic assay. The statistical significance of the A. fumigatus CFs concentrations on the proliferation of Caco-2 and WISH cells was estimated by ANOVA. Result were considered statistically significant if $p \leq 0.05$.

\section{RESULTS}

\section{Protein detection in $A$. fumigatus CF samples}

Six A. fumigatus CF samples were obtained in different time points $(24,72$ and $144 \mathrm{~h})$ under aerated $\left(20 \% \mathrm{O}_{2}\right) \quad(\mathrm{CF}$ AE-1, CF AE-3, CF AE-6) and non-aerated $\left(0 \% \mathrm{O}_{2}\right)$ (CF AN-1, CF AN-3, CF AN-6) conditions and analyzed by SDS-PAGE. During the course of prolonged aerated fermentation, A. fumigatus generated several low weight proteinaceous biomolecules (peaks marked 1-7; Figure 1). Electropherogram and densitometric analysis showed a presence of $43.6 \mathrm{kDa}$ protein in each sample (excluding A. fumigatus CF AN-1) (Figure 1). No significant difference was observed between proteinaceous products obtained during short fermentation of $A$. fumigatus, regardless of $\mathrm{O}_{2}$ conditions (CF AE- 1 and CF AN-1) (Figure 1a and 1e). However, several new products were detected in A. fumigatus CF AE-6 (Figure 1g) presented as the peaks marked with numbers $4-7$, corresponding to molecular weight of $15.4 ; 9.3$; 8.5; $6.45 \mathrm{kDa}$, respectively.

\section{Change of $\mathrm{pH}$ value in $A$. fumigatus CF samples}

Prior to inoculation of $A$. fumigatus, the $\mathrm{pH}$ of MEM broth was adjusted to $\mathrm{pH}$ 7.4. Under aerobic fermentation conditions the value increased to 8.57, 8.34 and 8.32 after $24 \mathrm{~h}, 72 \mathrm{~h}$ and $144 \mathrm{~h}$, respectively. Comparing to this, under anaerobic conditions $\mathrm{pH}$ value changed to $8.31,8.15$ and 8.07 after $24 \mathrm{~h}, 72 \mathrm{~h}$ 
and $144 \mathrm{~h}$, respectively.

\section{Inhibitory effect of $A$. fumigatus CF samples on trypsin and papain like proteinases}

Inhibitory effect of six A. fumigatus CFs on trypsin and papain like proteinases was examined. Inhibitory effect of $A$. fumigatus $\mathrm{CFs}$ on papain like proteinases was significant $(\mathrm{p}<0.05)$ and most pronounced when $A$. fumigatus CF-AE3 and A. fumigatus CF-AE6 were used $(41.95 \%$ and $43.21 \%$, respectively). No significant inhibitory effect was observed for trypsin like proteinases.

Direction of protein migration

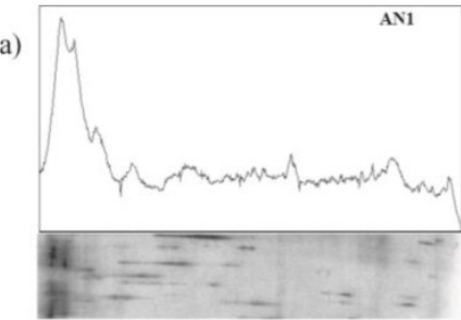

e)

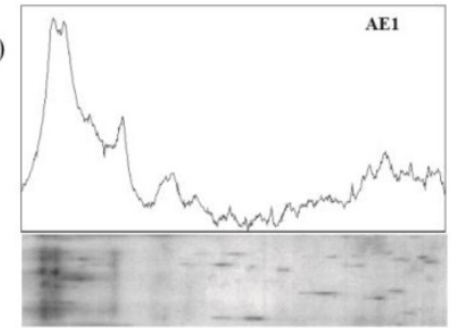

b)

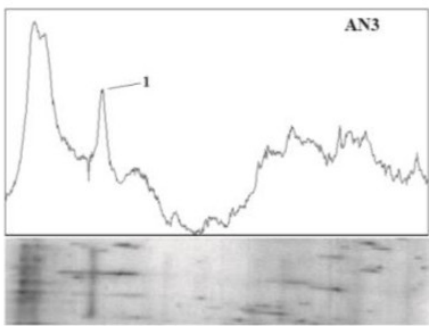

c)

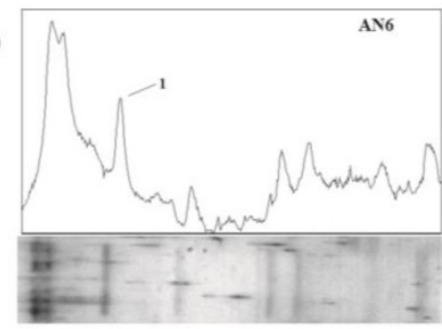

d)

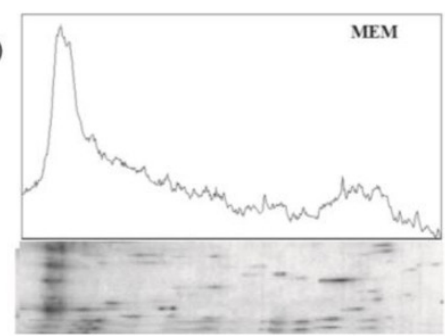

f)

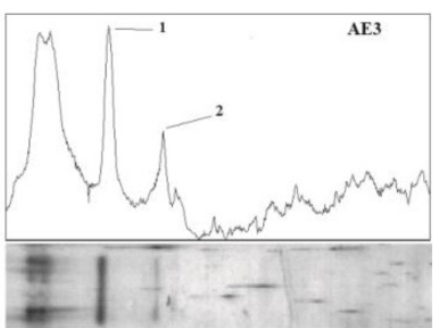

g)

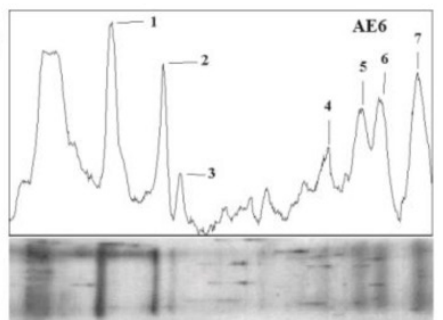

h)

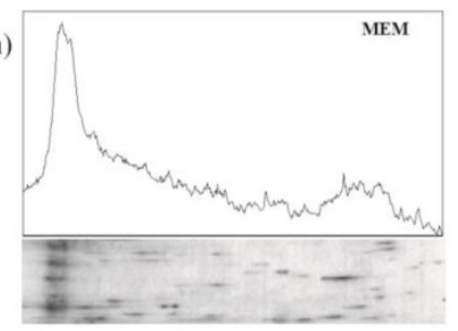

Figure I. Electropherogram and densitogram of the products detected in A. fumigatus CFs obtained in non-aerated conditions $\left(0 \% \mathrm{O}_{2}\right)$ after $24 \mathrm{~h}(\mathrm{AN}-\mathrm{I} ; \mathrm{a}), 72 \mathrm{~h}(\mathrm{AN}-3 ; \mathbf{b})$ and $\mathrm{I} 44 \mathrm{~h}(\mathrm{AN}-6 ; \mathrm{c})$ and in aerated conditions $\left(20 \% \mathrm{O}_{2}\right)$ after $24 \mathrm{~h}(\mathrm{AE}-\mathrm{I} ; \mathbf{e}), 72 \mathrm{~h}(\mathrm{AE}-3 ; \mathrm{f})$ and I $44 \mathrm{~h}(\mathrm{AE}-6 ; \mathbf{g})$. Protein traces are presented as the peaks marked with numbers I-7, corresponding to molecular weight of 43.6, 33.8, 31.2, I5.4, 9.3, $8.56 .45 \mathrm{kDa}$, respectively.

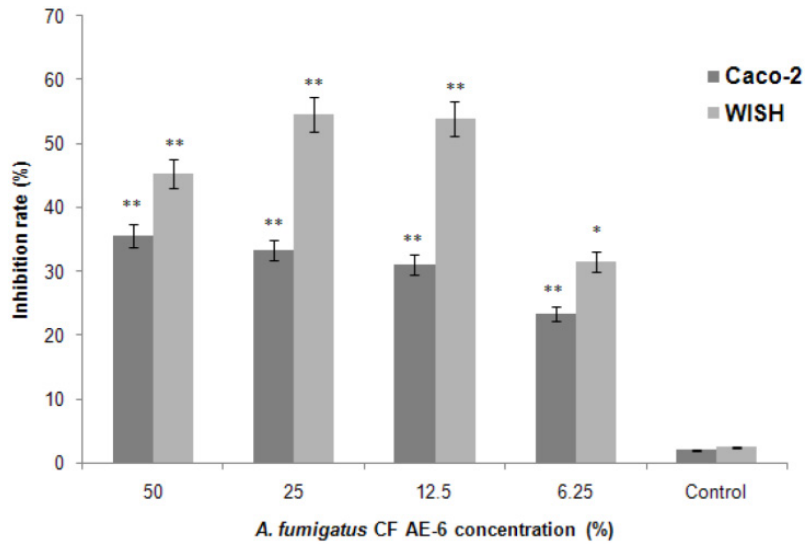

Figure 2. Long-term aerated conditions influence biomolecule generation in $A$. fumigatus CF AE-6 sample which exposed a statistically significant inhibition rate (IR, $\%)$ on Caco-2 and WISH cell line proliferation, comparing to cell IR in the media only $(t$-test; $* p<0.05 ; * *<<0.01)$. Assays were performed in triplicate and the data represent mean value of IR $\pm S D$.

\section{Cytotoxicity of $A$. fumigatus CF samples on Caco-2 and WISH cell lines}

Among all the six A. fumigatus CFs tested only $A$. fumigatus CF AE-6 exerted significant cytotoxic effect on Caco-2 $(p<$ $0.05)$ and WISH $(p<0.01)$ cell lines (data not shown). Results were expressed as percentage of inhibition rate (IR\%) on cell lines proliferation in comparison with cell proliferation in media alone (Figure 2). However, IR higher than $50 \%$ was demonstrated only for the WISH cell line and for CF AE-6 concentrations 25\% and $12.5 \%$ (Figure 2), while the lower IR was registered for Caco-2 cell line $(p<0.05)$ for the same extract.

\section{RSM correlation between $A$. fumigatus CFs $\mathrm{pH}$ value and proteases inhibition with oxygen saturation and fermentation time}

The obtained values of $\mathrm{pH}$ and inhibition of proteases were analyzed by RSM applying the multiple regression method to fit the second-order polynomial equation (equation 1). The statistical significance of the model equation, individual factors and their interactions were analyzed by the ANOVA. $F$ - and $p$-values for the fitted models indicated that they were statistically significant at the $95 \%$ confidence level, suggesting that this function is appropriate for fitting the data for both $\mathrm{pH}$ and inhibition of tested enzymes (Table 1). 
Table I. The results of ANOVA for RSM: $\mathrm{pH}$, inhibition of cysteine and serine proteases

\begin{tabular}{|c|c|c|c|c|c|c|}
\hline & $\begin{array}{l}\text { Source of } \\
\text { variance }\end{array}$ & $\begin{array}{l}\text { Suma of } \\
\text { Squares }\end{array}$ & $\begin{array}{l}\text { De- } \\
\text { grees } \\
\text { of } \\
\text { free- } \\
\text { dom }\end{array}$ & $\begin{array}{l}\text { Mean } \\
\text { Square }\end{array}$ & F-Value & p-value \\
\hline \multirow{7}{*}{$\mathrm{pH}$} & Model & 1.038884 & 4 & 0.259721 & 11.72892 & $0.0002^{*}$ \\
\hline & $t$ & 0.007789 & 1 & 0.007789 & 0.351748 & 0.5626 \\
\hline & $O$ & 0.815504 & 1 & 0.815504 & 36.82794 & $<0.0001^{*}$ \\
\hline & $t O$ & 0.149564 & 1 & 0.149564 & 6.754272 & $0.0210^{*}$ \\
\hline & $t^{2}$ & 0.032836 & 1 & 0.032836 & 1.482849 & 0.2435 \\
\hline & Residual & 0.310011 & 14 & 0.022144 & & \\
\hline & Cor Total & 1.348895 & 18 & & & \\
\hline \multirow{8}{*}{$\begin{array}{l}\text { Inhibition of } \\
\text { cysteine prote- } \\
\text { ases }\end{array}$} & Model & 3751.416 & 4 & 937.8541 & 58.90252 & $<0.0001^{*}$ \\
\hline & $t$ & 1739.072 & 1 & 1739.072 & 109.2235 & $<0.0001^{*}$ \\
\hline & $O$ & 1365.446 & 1 & 1365.446 & 85.75772 & $<0.0001^{*}$ \\
\hline & $t O$ & 247.9979 & 1 & 247.9979 & 15.57567 & $0.0015^{*}$ \\
\hline & $t^{2}$ & 346.0738 & 1 & 346.0738 & 21.73538 & $0.0004^{*}$ \\
\hline & Residual & 222.91 & 14 & 15.92214 & & \\
\hline & Cor Total & 3974.326 & 18 & & & \\
\hline & Model & 221.7724 & 4 & 55.44311 & 19.11203 & $<0.0001^{*}$ \\
\hline \multirow{6}{*}{$\begin{array}{l}\text { Inhibition of } \\
\text { serine proteas- } \\
\text { es }\end{array}$} & $t$ & 0.480761 & 1 & 0.480761 & 0.165725 & 0.6901 \\
\hline & $O$ & 6.261603 & 1 & 6.261603 & 2.158464 & 0.1639 \\
\hline & $t O$ & 0.057737 & 1 & 0.057737 & 0.019903 & 0.8898 \\
\hline & $t^{2}$ & 170.4013 & 1 & 170.4013 & 58.73975 & $<0.0001^{*}$ \\
\hline & Residual & 40.61334 & 14 & 2.900953 & & \\
\hline & Cor Total & 262.3858 & 18 & & & \\
\hline
\end{tabular}

"Statistically significant at the confidence level of $95 \%$.

Table 2. RSM - the values of parameters of the second-order polynomial equation

\begin{tabular}{llll}
\hline Term of equation & $\mathrm{pH}$ & $\begin{array}{l}\text { Inhibition of cysteine } \\
\text { proteases }\end{array}$ & $\begin{array}{l}\text { Inhibition of serine } \\
\text { proteases }\end{array}$ \\
\hline Intercept & 7.78 & -3.33 & 4.20 \\
$t$ & $5.49 \times 10^{-3}$ & 0.48 & 0.24 \\
$O$ & $3.39 \times 10^{-2}$ & 0.34 & $-6.63 \times 10^{-2}$ \\
$t O$ & $-1.80 \times 10^{-4}$ & $7.23 \times 10^{-3}$ & $1.10 \times 10^{-4}$ \\
$t^{2}$ & $-2.50 \times 10^{-5}$ & $-2.32 \times 10^{-2}$ & $-1.63 \times 10^{-3}$ \\
$R$ & 0.877 & 0.972 & 0.919 \\
$R$-adj & 0.850 & 0.963 & 0.894 \\
\hline
\end{tabular}

The level of oxygen and two-way interaction was statistically significant for $\mathrm{pH}$ values (Table 1). Furthermore, $p$-values of model terms showed that independent variables (time and the level of oxygen), their interaction and the time squared significantly affected the inhibition of cysteine protease, while only terms the time squared was statistically significant for the inhibition of serine proteases (Table 1). Values of the parameters of Equation (1) are given in Table 2. The value of $R$ and the adjusted $R$ showed a good correlation between the observed values and the predicted ones (Table 2).

The RSM curves were plotted to determine the optimum $\mathrm{pH}$ value and optimum inhibition of cysteine and serine proteases. At lower oxygen level, the $\mathrm{pH}$ value reached a plateau during long-term fermentation, while at higher oxygen level $\mathrm{pH}$ value reached its maximum and then slightly decreased in the later period of time (Figure 3). Inhibition of cys- teine proteases was found to increase rapidly at the beginning but at slower rate toward the end. Also as the time increased, the inhibition of these proteases increased in parallel, especially at the highest oxygen level (Figure 4a). With time the inhibition of serine proteases increased, especially at the lowest oxygen level, and decreased in the later period of the time (Figure $4 \mathrm{~b}$ ). Within the ranges of the extraction variables applied for development of the RSM, the maximum $\mathrm{pH}$ value (8.5) was predicted after $42 \mathrm{~h}\left(20 \% \mathrm{O}_{2}\right)$ (Figure 3) and the maximum inhibition of cysteine $(45.6 \%)$ and serine proteases $(12.8 \%)$ was predicted after $135 \mathrm{~h}\left(20 \% \mathrm{O}_{2}\right)$ and $42 \mathrm{~h}\left(0 \% \mathrm{O}_{2}\right)$, respectively (Figure 4).

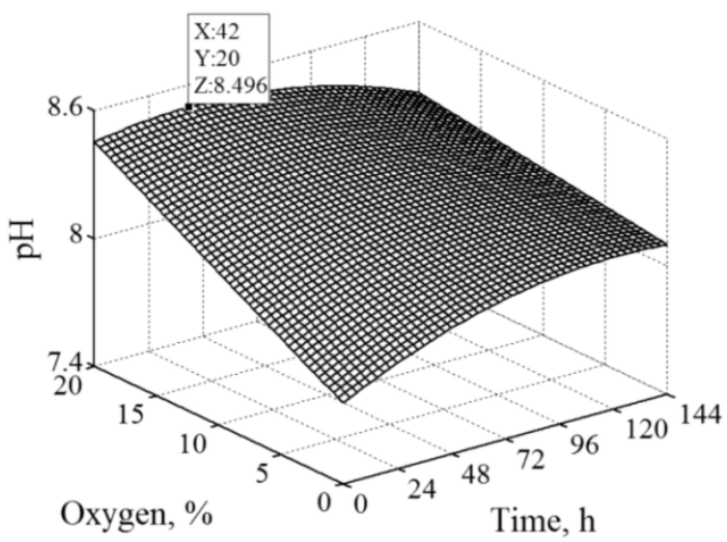

Figure 3. The response surface for $\mathrm{pH}$ as a function of time and the level of oxygen by RSM. Maximum values: time $(X)$, level of oxygen $(Y)$ and $\mathrm{pH}(\mathrm{Z})$.

\section{DISSCUSION}

Up to now, it was showed that A. fumigatus soluble metabolite profiles depended on different factors such as $\mathrm{pH}$ levels, temperature, light, substrates and media used $(20,21,22)$. Our results clearly demontrated the importance of time and aeration for $\mathrm{A}$. fumigatus metabolite synthesis and their cytotoxicity. The quantity and diversity of $A$. fumigatus extracellular low molecular weight biomolecules increase with time and aeration (Figure 1g). We confirmed the significance of our finding by using a mathematical model which corroborated the importance of aeration on $\mathrm{pH}$ value. The model suggested that $\mathrm{pH}$ remained alkaline, regardless of the presence of low molecular weight proteins which were secreted in aerated conditions. Many studies reported that A. fumigatus produces different active alkaline proteases during submerged fermentation $(28,29,30)$, which is consistent with our data. Our data demonstrated the change of $A$. fumigatus $\mathrm{CFs}$ protease inhibition profile based on different conditions. Model predicted that the maximum inhibition cysteine protease was 3.6 times higher than inhibition of serine protease (Figure 
4), suggesting that long-term aerated conditions have an influence on generation of biomolecules with inhibitory activity on cysteine proteases. These metabolites are potential compounds capable of reacting with free thiol groups and consequently inhibiting different classes of enzymes with functional thiol group at their active sites. In this study we demonstrated some in vitro activity which may be associated with $A$. fumigatus protease or protease inhibitors that can be significant during infection and may interplay with the host cells. Importance of proteases and/or proteases inhibitors resulted in formation of database that contains information for about 2000 proteases and 400 inhibitors [31].

Having in mind the importance of microbial protease and/or protease inhibitors for host cells cytotoxicity, we screened A. fumigatus CFs samples for cytotoxic effect against Caco-2 and WISH cell lines. Our data demonstrated significant inhibition of cell proliferation when extracts after prolonged aerated conditions were used (A. fumigatus CF AE6) (Figure 2). It is shown that $A$. fumigatus $C F$ expressed a high cytotoxicity on murine macrophages under highly aerated conditions [32]. However, in our study cytotoxic effect was expressed by CFs obtained on day 6 and condition with $20 \% \mathrm{O}_{2}$, while other study showed cytotoxicity with $A$. fumigatus CF obtained after $15 \mathrm{~h}$ [32]. The samples obtained during short-term fermentation (day 1 and 3) did not express a significant cytotoxicity in this study. It may be concluded that biomolecules produced under long-term aerated conditions corresponding to molecular weight of 15.4; 9.3; 8.5 and $6.45 \mathrm{kDa}$ are at least partially responsible for expressed cytotoxicity. This is in correlation with the fact that biosynthesis of low weight biomolecules is complex and they are often produced late in fungal development [11]. This is known for oxylipins which regulate Aspergillus development and mycotoxin production, therefore all this indicates that observed small biomolecules can be further investigated as Aspergillus quorum sensing molecules [33].

The oxygen availability during fungal pathogenesis may play a critical role in the outcome of infection from the perspective of both the host and the fungus [34]. It can be suggested that the ability of $A$. fumigatus to adapt to long-term aerated conditions can be significant mechanism for virulence factors generation during infection. These finding may prove to be clinically beneficial, indicating that manipulation of oxygen (and/or $\mathrm{CO}_{2}$ ) levels at sites of human fungal infection may be a promising therapeutic approach [35]. It is also known that ventilator-associated pneumonia is a common hospital infection, especially in intensive care units (ICU) patients. Study showed that patients with pulmonary IA and high mortality rate had a longer ICU stay and a more extended period of mechanical ventilator dependency [36]. Among numerous airborne molds, A. fumigatus is the most common agent responsible for causing diseases in critically ill mechanically ventilated patients [37] highlighting the most important finding of this study related to biological activity of A. fumigatus samples obtained under long-term aerated experimental conditions, similar to the lungs of the mechanically ventilated patient without applied therapy. A. fumigatus metabolite production is often strain-specific and may tolerate different oxygen levels so father study can be improved by testing the influence of different oxygen concentrations and more fungal strains (including clinical isolates) in the same way. Also, the onset and the ooutcomes of $A$. fumigatus infection depend on exogenous and endogenous conditions and their interaction [2], so the animal models will prove significant contribution to further investigations of described biomolecules [38, 39].
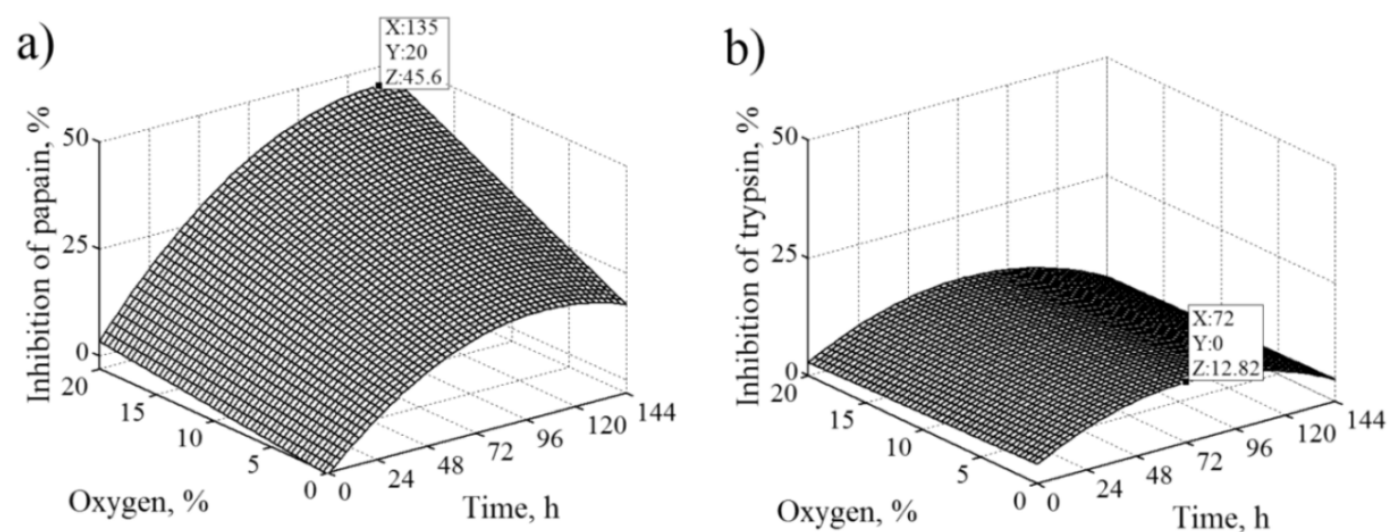

Figure 4. The response surface for inhibition of cysteine proteases as a function of the time and the level of oxygen (a) by RSM; Response surface for inhibition of serine proteases as a function of the time and the level of oxygen (b) by RSM. Maximum values: time (X), level of oxygen ( $Y$ ) and inhibition of proteases (Z). 
In conclusion, the genus Aspergillus represented with $A$. fumigatus is a threat to public health because is associated with high mortality rate in high risk patients, especially in those with cystic fibrosis, asthma, chronic obstructive lung disease and/or immunosuppression [3]. Here we demonstrated that $A$. fumigatus excretes low molecular weight biomolecules in positive correlation with time and oxygenation associated with inhibition of cysteine proteases and cytotoxicity against WISH and Caco- 2 cell lines. These in vitro findings may support a presumption that during in vivo conditions similar products are expressed and may act as virulence factors important for A. fumigatus pathogenicity and severity of diseases, which can contribute to better understanding of these diseases. Further investigations are needed to select, research and analyze low molecule weight biomolecules produced by A. fumigatus under long-term aerated conditions, including their examination as virulence factors, diagnostic biomarkers or therapeutic targets.

\section{ACKNOWLEDGMENT}

This study was supported by Ministry of Education, Science and Technological development Republic of Serbia (grants no 175034 and 175033) and by the Ministry of Education Science and Technology Republic of Slovenia - Scientific and Educational Foundation of Republic of Slovenia (Ad Futura). We thank Jasmina Nikodinovic-Runic, PhD (Institute of Molecular Genetics and Genetic Engineering, Belgrade, Serbia) for manuscript review and English correction.

\section{CONFLICT OF INTEREST}

V. A. A. has served as a consultant for Pfizer and MSD and has served on the speakers' bureaus of Pfizer, MSD and Providens and received grant support from Pfizer. All other authors: no potential conflicts of interest.

\section{REFERENCES}

1. Neofytos D, Horn D, Anaissie E, Steinbach W, Olyaei A, Fishman J, Pfaller M, Chang C, Webster K, Marr K. Epidemiology and outcome of invasive fungal infection in adult hematopoietic stem cell transplant recipients: analysis of Multicenter Prospective Antifungal Therapy (PATH) Alliance registry. Clin Infect Dis. 2009; 48(3):265-73.

2. Lass-Flörl C, Roilides E, Löffler J, Wilflingseder D, Romani L. Minireview: host defence in invasive aspergillosis. Mycoses. 2013; 56(4):403-13.

. Denning DW. Invasive aspergillosis. Clin Infect Dis. 1998; 26: 781-803.

4. Binder U, Lass-Flörl C. New insights into invasive aspergillosis-from the pathogen to the disease. Curr Pharm Des. 2013; 19(20):3679-88.

5. Farid S, Mohamed S, Devbhandari M, Kneale M, Richardson M, Soon SY, Jones MT, Krysiak P, Shah R, Denning DW, Rammohan K. Results of surgery for chronic pulmonary aspergillosis, optimal antifungal therapy and proposed high risk factors for recurrence - a National Centre's experience. J Cardiothorac Surg. 2013;8(1):180. [Epub ahead of print]

6. Coleman JJ, Ghosh S, Okoli I, Mylonakis E. Antifungal Activity of Microbial Secondary Metabolites. PLoS One 2011; doi: 10.1371/journal.pone.0025321.

7. Kosalec I, Pepeljnjak S. Mycotoxigenicity of clinical and environmental Aspergillus fumigatus and A. flavus isolates. Acta Pharm 2005; 55: 365-75.

8. Sugui JA, Pardo J, Chang CY, Zarember KA, Nardone G, Galvez EM, Mullbacher A Gallin JI, Simon MM, Kwon-Chung KJ. Gliotoxin Is a Virulence Factor of Aspergillus fumigatus: gliP Deletion Attenuates Virulence in Mice Immunosuppressed with Hydrocortisone. Eukaryotic Cell 2007; 6: 1562-9.
9. Gauthier T, Wang X, Sifuentes Dos Santos J, Fysikopoulos A, Tadrist S, Canlet C, Artigot MP, Loiseau N, Oswald IP, Puel O. Trypacidin, a spore-borne toxin from Aspergillus fumigatus, is cytotoxic to lung cells. PLoS One 2012; doi:10.1371/journal.pone.0029906

10. Rementeria A, López-Molina N, Ludwig A, Vivanco AB, Bikandi J, Pontón J, Garaizar J. Genes and molecules involved in Aspergillus fumigatus virulence. Rev Iberoam Micol. 2005; 22: 1-23.

11. Calvo A.M, Wilson R.A, Bok J.W, Keller NP. Relationship between Secondary Metabolism and Fungal Development. Microbiol Mol Biol Rev 2002; 66: 447-59.

12. Bauerová V, Pichová I, Hrusková-Heidingsfeldová O. Fungal gene-encoded peptidase inhibitors. Curr Med Chem. 2013; 20(25):3041-8.

13. Kamei K, Watanabe A, Nishimura K, Miyaji M. Culture filtrate of Aspergillus fumigatus and its cytotoxic activity against leukocytes. Nihon Ishinkin Gakkai Zasshi 2002; 43: 37-41

14. Donnelly S, Dalton JP, Robinson MW. How pathogen-derived cysteine proteases modulate host immune responses. Adv Exp Med Biol. 2011;712:192-207.

15. Watanabe A, Kamei K, Sekine T, Waku M, Nishimura K, Miyaji M, Kuriyama T. Immunosuppressive substances in Aspergillus fumigatus culture filtrate. J Infect Chemother. 2003; 9: 114-21.

16. Khoufache K, Puel O, Loiseau N, Delaforge M, Rivollet D, Coste A, Cordonnier C, Escudier E, Botterel F, Bretagne S. Verruculogen associated with Aspergillus fumigatus hyphae and conidia modifies the electrophysiological properties of human nasal epithelial cells. BMC Microbiol. 2007; 7:5

17. Ben-Ami R, Lewis RE, Leventakos K, Kontoyiannis DP. Aspergillus fumigatus inhibits angiogenesis through the production of gliotoxin and other secondary metabolites. Blood 2009; 114: 5393-9.

18. Daly P, Verhaegen S, Clynes M, Kavanagh K. Culture filtrates of Aspergillus fumigatus induce different modes of cell death in human cancer cell lines. Mycopathologia 1999;146: 67-74.

19. Balde ES, Andolfi A, Bruyère C, Cimmino A, Lamoral-Theys D, Vurro M, Damme MV, Altomare C, Mathieu V, Kiss R, Evidente A. Investigations of fungal secondary metabolites with potential anticancer activity. J Nat Prod 2010; 73:969-71.

20. da Silva RR, de Freitas Cabral TP, Rodrigues A, Cabral H. Production and partial characterization of serine and metallo peptidases secreted by Aspergillus fumigatus Fresenius in submerged and solid state fermentation. Braz J Microbiol. 2013; 44(1):235-43.

21. Farnell E, Rousseau K, Thornton DJ, Bowyer P, Herrick SE. Expression and secretion of Aspergillus fumigatus proteases are regulated in response to different protein substrates. Fungal Biol. 2012; 116(9):1003-12.

22. Fuller KK, Ringelberg CS, Loros JJ, Dunlap JC. The fungal pathogen Aspergillus fumigatus regulates growth, metabolism, and stress resistance in response to light. MBio. 2013; 4(2). doi: 10.1128/mBio.00142-13.

23. Bradford MM. A rapid and sensitive method for the quantitation of microgram quantities of protein utilizing the principle of protein-dye binding. Anal Biochem 1976; 72: 248-54.

24. Switzer RC, Merril CR, Shifrin S. A highly sensitive silver stain for detecting proteins and peptides in polyacrylamide gels. Anal Biochem 1979; 98: 231-7.

25. Florkin M, Stotz EH. Comprehensive Biochemistry. Amsterdam, The Netherlands: Elsevier. 1965.

26. Masters JR. HeLa cells 50 years on: the good, the bad and the ugly. Nat Rev Cancer. 2002; 2(4):315-9.

27. Videmann B, Mazallon M, Tep J, Lecoeur S. Metabolism and transfer of the mycotoxin zearalenone in human intestinal Caco-2 cells. Food Chem Toxicol. 2008; 46(10):3279-86

28. Santos R, Firmino AA, de Sá CM, Felix CR. Keratinolytic activity of Aspergillus fumigatus fresenius. Current Microbiology 1996; 33: 364-70.

29. Ikegami Y, Amitani R, Murayama T, Nawada R, Lee WJ, Kawanami R, Kuze F. Effects of alkaline protease or restrictocin deficient mutants of Aspergillus fumigatus on human polymorphonuclear leukocytes. Eur Respir J. 1998; 12: 607-11.

30. Anthony T, Raj KC, Rajendran A, Gunasekaran P. Inhibition of proteases during fermentation improves xylanase production by alkali tolerant Aspergillus fumigatus ARl. J Biosci Bioeng 2003; 96:394-96.

31. [Internet] MEROPS database. http://merops.sanger.ac.uk/inhibitors/

32. Kristan SS, Kern I, Music E. Invasive pulmonary aspergillosis. Respiration. 2002; 69(6):521-5.

33. Affeldt K, Brodhagen M, Keller N. Aspergillus Oxylipin Signaling and Quorum Sensing Pathways Depend on G Protein-Coupled Receptors. Toxins 2012; 4(9): 695-717.

34. Grahl N, Shepardson KM, Chung D, Cramer RA. Hypoxia and fungal pathogenesis: to air or not to air? Eukaryot Cell. 2012; 11(5):560-70.

35. Grahl N, Cramer RA. Regulation of hypoxia adaptation: an overlooked virulence attribute of pathogenic fungi? Med Mycol. 2010; 48(1):1-15.

36. Vandewoude KH, Blot SI, Benoit D, Colardyn F, Vogelaers D. Invasive aspergillosis in critically ill patients: attributable mortality and excesses in length of ICU stay and ventilator dependence. J Hosp Infect. 2004; 56(4):269-76.

37. Watanabe A, Kamei K, Sekine T, Waku M, Nishimura K, Miyaji M, Tatsumi K, Kuriyama T. Effect of aeration on gliotoxin production by Aspergillus fumigatus in its culture filtrate. Mycopathologia 2004; 157: 19-27.

38. Speth C, Hagleitner M, Ott HW, Würzner R, Lass-Flörl C, Rambach G. Aspergillus fumigatus activates thrombocytes by secretion of soluble compounds. I Infect Dis. 2013; 207(5):823-33.

39. El-Muzghi AA, Mirkov I, Djokic J, Popov Aleksandrov A, Miljkovic D, Glamoclija J, Kataranovski D, Kataranovski M. Regional cytokine responses to pulmonary aspergillosis in immunocompetent rats. Immunobiology. 2013; 218(12):1514-23. 